\title{
Polymer Derived Silicon Oxycarbide Ceramic Monoliths: Microstructure Development and
}

\section{Associated Materials Properties.}

Pradeep Vallachira Warriam Sasikumar ${ }^{a^{*}}$, Gurdial Blugan $^{a}$, Nicola Casati $^{b}$, Eirini Kakkava $^{c}$, Panusa Giulia ${ }^{c}$, Demetri Psaltis $^{c}$, Jakob Kuebler $^{a}$

${ }^{a}$ Laboratory of high performance ceramics, Empa - Swiss Federal Laboratories for Material

Science and Technology, 8600 Dübendorf, Switzerland

${ }^{b}$ Swiss light source, Paul Scherrer Institut, WLGA/229, Villigen PSI, Switzerland

${ }^{c}$ Optics Laboratory, School of Engineering, École Polytechnique Fédérale De Lausanne, Lausanne, Switzerland

* Corresponding Author: Pradeep.Vallachira-Warriam@empa.ch

\section{Abstract}

Polymer derived SiOC and SiCN ceramics (PDCs) are interesting candidates for additive manufacturing techniques to develop micro sized ceramics with the highest precision. PDCs are obtained by the pyrolysis of crosslinked polymer precursors at elevated temperatures. Within this work, we are investigating PDC SiOC ceramic monoliths synthesized from liquid polysiloxane precursor crosslinked with divinylbenzene for fabrication of conductive electromechanical devices. Microstructure of the final ceramics was found to be greatly influenced by the pyrolysis temperature. Crystallisation in SiOC ceramics starts above $1200{ }^{\circ} \mathrm{C}$ due to the onset of carbothermal reduction leading to the formation of $\mathrm{SiC}$ and $\mathrm{SiO} 2$ rich phases. Microstructural characterization using ex-situ X-ray diffraction, FTIR, Raman spectra and microscopy imaging confirms the formation of nano crystalline $\mathrm{SiC}$ ceramics at $1400{ }^{\circ} \mathrm{C}$. The electrical and This document is the accepted manuscript version 1 of the following article: Sasikumar, P. V. W., Blugan, G., Casati, N., Kakkava, E., Panusa, G., Psaltis, D., \& Kuebler, J. (2018). Polymer derived silicon oxycarbide ceramic monoliths: microstructure development and associated materials properties. Ceramics Internationa1, 44(17), 20961-20967. https://doi.org/10.1016/j.ceramint.2018.08.102 
mechanical properties of the ceramics are found to be significantly influenced by the phase separation with samples becoming more electrically conducting but with reduced strength at $1400{ }^{\circ} \mathrm{C}$. A maximum electrical conductivity of $10^{1} \mathrm{~S} \mathrm{~cm}-1$ is observed for the $1400{ }^{\circ} \mathrm{C}$ samples due to enhancement in the ordering of the free carbon network. Mechanical testing using the ball on 3 balls (B3B) method revealed a characteristic flexural strength of $922 \mathrm{MPa}$ for $1000{ }^{\circ} \mathrm{C}$ amorphous samples and at a higher pyrolysis temperature, materials become weaker with reduced strength.

Keywords: Polymer derived ceramics; Casting; Sintering; Electrical properties; Mechanical Properties

\section{Introduction}

Silicon based Polymer Derived Ceramics (PDCs) such as SiOC, SiCN and SiC with Si, C, O and N in their basic structural unit is a broad class of ceramics prepared by the pyrolysis of crosslinked polymer precursors in a controlled atmosphere and is generally classified according to their basic structural networks[1]. PDCs are synthesized at temperatures above $1000{ }^{\circ} \mathrm{C}$ and have been widely studied as materials for different functional applications in the past couple of decades. Among PDCs, SiOC ceramics are novel amorphous materials where some of the bridging oxygen atoms in the silica unit are replaced with carbon, forming a network of mixed SiOC units along with a disordered free carbon network [2-11]. Structural stoichiometry of SiOC ceramics significantly influences the materials stability towards oxidation and other features. Microstructural development of SiOCs mainly depends on the starting precursors and pyrolysis conditions with phase separation in to $\mathrm{SiC}$ and $\mathrm{SiO}_{2}$ rich phases starting above $1300{ }^{\circ} \mathrm{C}$ due to the onset of carbothermal reduction. Microstructural developments proceeds with 
redistribution of $C$ and $O$ atoms around silicon during ceramisation at temperatures above 400 ${ }^{\circ} \mathrm{C}$ as evidenced from MAS NMR, $\mathrm{X}$-ray diffraction and other complementary techniques [12-15]. Structural stoichiometry of $\mathrm{SiOC}$ is generally represented as $\mathrm{SiO}_{2(1-x)} \mathrm{C}_{\mathrm{x}}+\mathrm{YC}_{\text {free. }}$. Carbon content in the $\mathrm{SiOC}$ ceramics can reach a maximum of up to $70 \mathrm{~mol} \%$ depending on the starting preceramic polymer (PCP) materials used. SiOC ceramics exhibit remarkable physical properties superior to conventional silica glasses, which makes it an interesting candidate for use in aggressive harsh environments. The presence of excess free carbon is found to enhance the electromechanical properties of SIOC ceramics, making it suitable for development as materials for various applications such as anode materials for Li-ion batteries, gas sensors, implants for biomedical applications etc.[15-19].

High precision ceramic components based on PDCs can be manufactured using additive manufacturing techniques. Additive manufacturing is currently gaining attention as a subject for micro-manufacturing of functional ceramics $[20,21]$. The structural, electrical, mechanical and biological properties of PDCs can be controlled by tailoring the polymer architecture of the starting polymer precursors $[18,19,22-25]$. The shape of the final ceramic materials will remain identical to that of preceramic green body apart from experiencing volumetric shrinkage and an increase in density. Microfabrication of specific ceramic shapes involves a series of processes starting from selection of ideal polymer precursors. Detailed steps of microfabrication process are given in Figure 1a. The steps include, design and fabrication of specific micromoulds followed by casting of selected polymer precursors. Cross-linking of PCP precursors serves as an important part of the process to fabricate preceramic green bodies. A platinum catalyzed hydrosililation method is used in our approach for crosslinking the starting precursors. Other 
methods in practice for crosslinking of PCP precursors include sol-gel method, thermal crosslinking and photo crosslinking using respective initiator agents [11, 22, 26, 27]. Cross-linked preceramic green bodies are then pyrolysed at higher temperatures to obtain final PDC materials. Disperison of nano fillers such as $\mathrm{CNTS}, \mathrm{TiO}_{2}$ etc. in the polymer precursors is also an important approach to enhance the properties of these materials [28-31]. Convincing bioactivities of SiOC ceramics makes them a promising candidate for fabrication of biomedical implants with enhanced blood compatibility $[18,19,32]$.

Within this work, polymer derived SiOC ceramic monoliths are synthesised from crosslinked polysiloxane networks. Samples have been pyrolysed at different temperatures to correlate the materials properties with microstructure development. Phase separation at higher pyrolysis temperatures was found to have a significant influence on the structural and physical properties of these materials.

\section{Materials and methods}

\subsection{Synthesis of SiOC ceramics}

Polyhydromethyl siloxane (PHMS) (Sigma Aldrich, Switzerland, MW 1900), divinyl benzene (DVB) and a platinum Karstedt's catalyst (Platinum(0)-1,3-divinyl-1,1,3,3-tetramethyldisiloxane complex solution in xylene, Pt $2 \%$ ) were purchased from Sigma Aldrich and used as received. In a typical preparation, $2 \mathrm{~g}$ of divinyl benzene is mixed with $~ 700 \mathrm{ppm}$ of Pt catalyst by stirring for 15 minutes. $1 \mathrm{~g}$ of PHMS is then added to the DVB drop by drop with continuous stirring. DVB content is two times in weight with respect to PHMS to achieve the maximum free carbon content in the final ceramics. The hydrosilylation reaction between PHMS and DVB is highly exothermic and a water bath with cold water is used to control the reaction temperature. The 
mixture after stirring for 30 minutes is cast in to teflon moulds as shown in Figure 1a and left for gelation. Gelation is observed in half an hour and the gels are left for drying overnight at ambient conditions.

Preceramic polymer films are then removed from the teflon moulds and discs of $7 \mathrm{~mm}$ were cut for pyrolysis. Pyrolysis is carried out in a tubular furnace using an alumina tube under controlled argon atmosphere (Carbolite, Germany). Samples were pyrolysed at 800, 900, 1000, 1100, 1200, 1300 and $1400^{\circ} \mathrm{C}$ respectively with heating and cooling rates of $50^{\circ} \mathrm{C} / \mathrm{hr}$ and a holding time of 1 $\mathrm{hr}$ at the maximum temperature. We focus mainly on samples pyrolysed at $1000{ }^{\circ} \mathrm{C}$ and $1400{ }^{\circ} \mathrm{C}$ having major changes in their respective microstructures.

a)

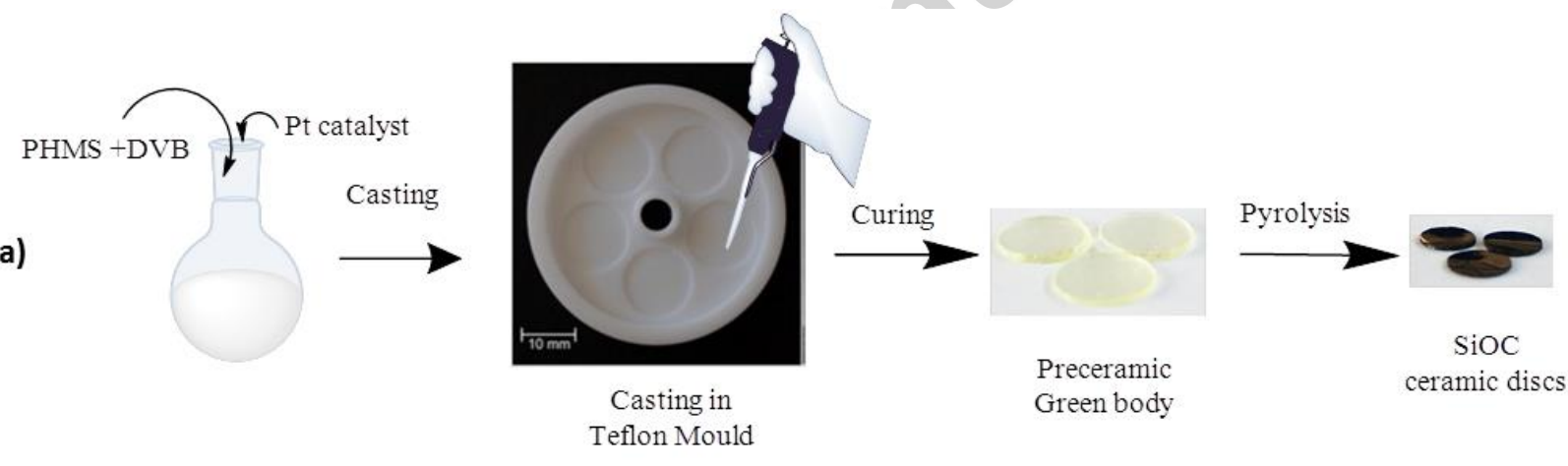

b)

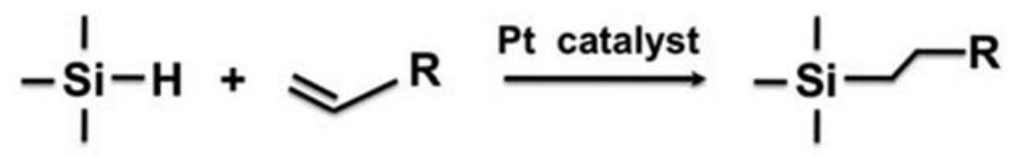

Figure 1. a. Schematic representation of the PDC fabrication process and b. proposed hydrosililation reaction scheme

\subsection{Structural characterisation}

FTIR spectra were recorded in Tensor 27, Bruker (Massachusetts, United states) using a Golden Gate ATR and applying a constant pressure during the measurement. The phase separation at 
each pyrolysis temperature was studied using X-ray diffraction experiments at the Material Science Beamline of the Swiss Light Source [33]. For this scope a wavelength of $0.56360 \AA$, as calibrated using a LaB6 diffraction standard, was used in transmission mode. Diffraction was collected on a Pilatus $6 \mathrm{M}$ detector and subsequently reduced to a standard diffractogram using Dioptas. Raman spectra of the ceramic monolith were recorded on a confocal Raman spectrometer (Renishaw, UK) by using a laser beam with an excitation wavelength of $488 \mathrm{~nm}$ to determine the amount of ordering of the carbon with temperature.

The microstructure development in pyrolysed SiOC ceramic discs were examined using SEM (VEGA Plus 5136 MM, Tescan instruments, Brno - Kohoutovice, Czech Republic) and FESEM (FEI Nova NanoSEM, FEI, Hillsboro, Oregon, USA ) techniques.

Electrical conductivity of the ceramics is measured at room temperature using a collinear four probe (Microworld, Grenoble, France) and a Keithley 2450 source meter (Tektronix UK Ltd., Berkshire, England). The probe had a spacing of $1.26 \mathrm{~mm}$ between the contact pins. Meaurements have been performed under a current bias technique where a current of $1 \mu \mathrm{A}$ is given through the outer probes and the corresponding voltage between inner probes is measured. Resistance has been measured by measuring voltage with a step of 100 seconds. From the obtained resistance, conductivity is calculated using the following formulae.

Resistance $(R)=R_{\text {mean }} * f, \quad$ eq. (1)

$f=$ the geometric correction factor, which is a ratio of diameter of the disc (d) to probe separation (s). f value used in the present experiment is 2.9289 corresponding to a d/s of 4.0. 
Ten resistance values were aquired from each sample. Conductivity is calculated from the obtained resistance using the equation given below

$\sigma=\frac{1}{(R * t)}, \mathrm{t}=$ thickness of the disc, eq. (2)

Mechanical characterisation of the ceramic discs was performed by measuring the biaxial flexural strength using the ball-on-three-balls (B3B) test method. The B3B technique is mainly used for determining the strength of brittle ceramic materials, generally applied on thin disc shaped materials. A more detailed discription of the B3B technique can be found in the literatures[34-36].

The strength was calculated according to the following equation :

$\sigma=f_{(\alpha, \beta, u)} * F / t^{2} \quad$ eq. (3)

Where $\sigma$ is the strength [MPa], $F$ the applied force $[N]$, and $t[\mathrm{~mm}$ ] the thickness of the specimen. " $f$ " is a dimensionless factor depending on the ratio of thickness to the radius of disc $(\alpha=t / R)$, the ratio of the support radius of the 3 balls to the $\operatorname{discs} \operatorname{radius}(\beta=R a / R)$ and the Poisson's ratio of the material which was in this case defined as 0.22 . The radii of the balls were $1.9 \mathrm{~mm}$. The cross head displacement was set up to $5 \mathrm{~mm} / \mathrm{min}$. The calculation of the Weibull modulus was performed according to standard EN843-5 (2006).

\section{Results and discussion}

Preceramic green body and sintered ceramic samples are presented in Figure 1a. Gelation time for the crosslinked polymer was in the range of 30 minutes to one hour and the gel films were easily separated from the moulds after overnight drying in a desicator. The removed gels were 
transparent and flexible in nature and the gels become hard and brittle after the curing step at

$80^{\circ} \mathrm{C}$. Information about weight loss, ceramic yield and shrinkage of the samples after pyrolysis at different temperatures are given in Table1. Ceramic discs, after pyrolysis have a shiny black appearance representing formation of disordered free carbon network along with the mixed SiO-C ceramic matrix. It is important to have flat samples for materials characterisations and this is achieved by applying slow heating/cooling rates which helps to limit the warpage at higher temperatures. The ceramic yield after $1000{ }^{\circ} \mathrm{C}$ is about $~ 71 \%$ and no significant shrinkage and weight loss were observed above this pyrolysis temperature. Ceramic yield is calculated based on weightloss happening at higher temperatures due to the loss of organics and other volatile units during polymer to ceramic conversion. The polymer to ceramic conversion is complete at $1000{ }^{\circ} \mathrm{C}$ and above this temperature, mainly phase separation of oxygen rich and carbon rich species occurs with the formation of nanocrystalline SiC at temperatures above $1250{ }^{\circ} \mathrm{C}$. Thermogravimetric data of the studied polysiloxane composition is already available in literatues $[15,37,38]$.

\section{Table 1.}

FTIR spectra of the preceramic greenbodies and samples sintered at 1000 and $1400{ }^{\circ} \mathrm{C}$ are presented in Figure 2. Bands corresponding to polymer backbone and attached functional groups can be clearly seen in the spectra corresponding to preceramic greenbodies. The spectra of crosslinked green body does not have any bands corresponding to $\mathrm{Si}-\mathrm{H}$ bands confirming the complete hydrosililation reaction between $\mathrm{Si}-\mathrm{H}$ in polysiloxane and vinyl group in divinyl benzene. After pyrolysis at $1000{ }^{\circ} \mathrm{C}$, many bands disappear due to polymer to ceramic conversion and mainly bands corresponding to $\mathrm{Si}-\mathrm{O}$ and $\mathrm{Si}-\mathrm{C}$ bonds are present in the spectra of 
the pyrolysed samples. The process of ceramisaion leads to formation of mixed Si-O-C network with silicon bonding to both oxygen and carbon and no evidenece for C-O linkage is observed, which is in agreement with the data already reported elsewhere[1, 5, 8, 11, 15, 27, 39]. With an increase in pyrolysis temperature, to $1400{ }^{\circ} \mathrm{C}$, Si-C bands become dominant with reduced intensity for bands corresponding to Si-O. This is due to the onset of carbothermal reduction leading to the formation of nanocrystalline $\mathrm{Si}-\mathrm{C}$ by consuming $\mathrm{Si}-\mathrm{O}$ and carbon according to the following equations [8]

$$
\begin{aligned}
& \mathrm{SiO}_{2}(\mathrm{~s})+C_{(\mathrm{s})} \rightarrow \mathrm{SiO}_{(\mathrm{g})}+\mathrm{CO}_{(\mathrm{g})} \\
& \mathrm{SiO}_{(\mathrm{g})}+2 C_{(\mathrm{s})} \rightarrow \mathrm{SiC}_{(\mathrm{s})}+\mathrm{CO} \mathrm{O}_{(\mathrm{g})}
\end{aligned}
$$

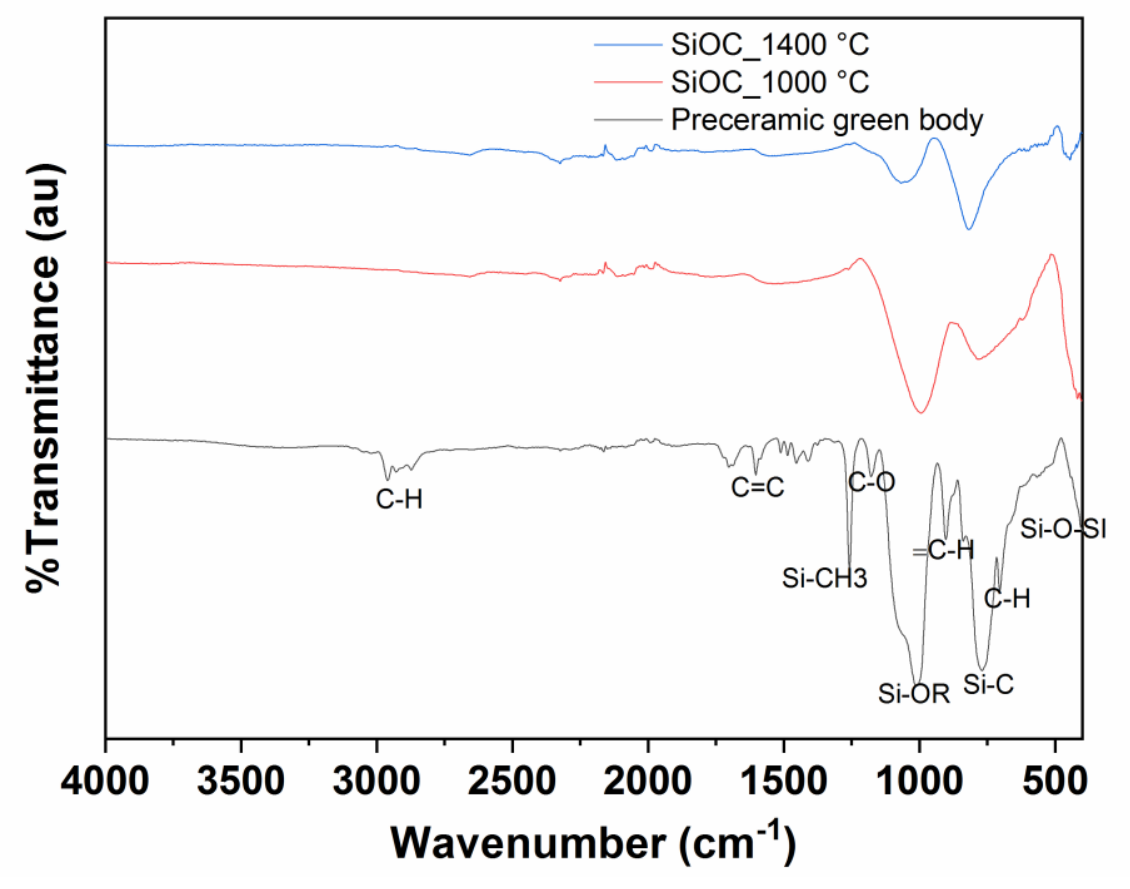

Figure 2. FTIR spectra of preceramic greenbody and samples pyrolysed at 1000 and $1400{ }^{\circ} \mathrm{C}$ respectively 
The diffraction patterns of SiOC ceramics sintered at different temperatures are presented in Figure 3. Patterns have been recorded for preceramic greenbodies and SiOC ceramic materials pyrolysed at $800-1400{ }^{\circ} \mathrm{C}$ with an interval of $100{ }^{\circ} \mathrm{C}$ between each sample, clearly showing the onset of crystallization. Patterns corresponding to preceramic greenbodies are completely amorphous. Samples pyrolysed at $800-1200{ }^{\circ} \mathrm{C}$ are also amorphous in nature, although presenting a different character, visible in the changed angular dependence of the intensity curve. Initiation of phase separation process can be seen above $1200{ }^{\circ} \mathrm{C}$. Broad but formed peaks, corresponding mainly to $\mathrm{SiC}$ type structure (sphalerite) can be seen forming at $1300^{\circ} \mathrm{C}$

with more intensity and sharper features at $1400^{\circ} \mathrm{C}$.

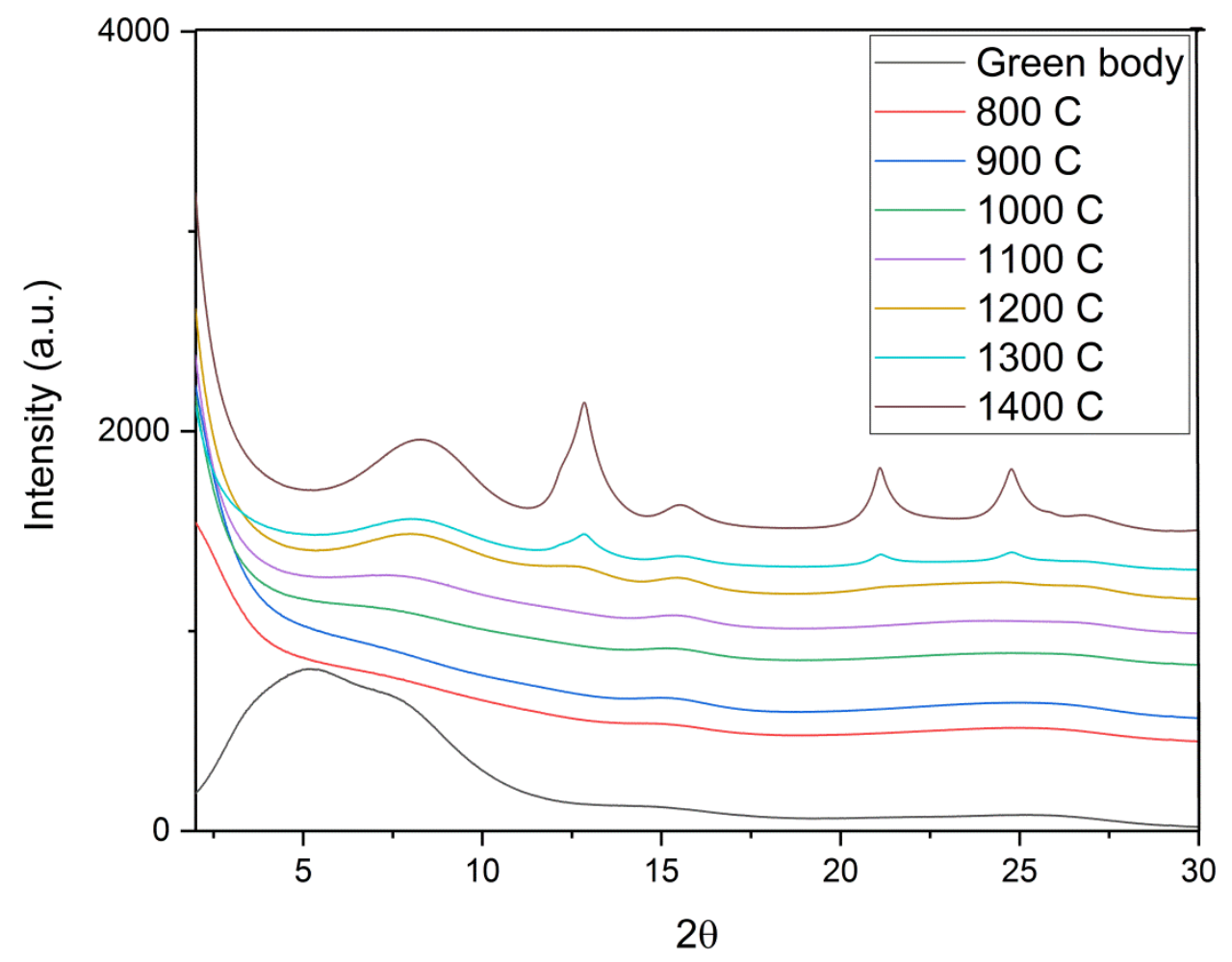


Figure 3. Diffraction pattern of preceramic greenbody and samples sintered at $800,900,1000$, $1100,1200,1300$ and $1400{ }^{\circ} \mathrm{C}$ respectively. Patterns are linearly shifted along the y axis (arbitrary units) from the preceramic green body to the highest temperature for better reading.

The peaks corresponding to SiC type ceramics are formed due to the onset of carbothermal reduction[1]. The crystallization tendency gets higher for 1300 and $1400{ }^{\circ} \mathrm{C}$ samples. These phase separation with formation of nano crystalline phases has significant influence on the properties of these ceramics.

The diffraction patterns are further supported by SEM and FESEM investigations (Figure 4) with appearance of whisker like structures on the ceramic surfaces after pyrolysis at $1400^{\circ} \mathrm{C}$. Formation of these whiskers also leads to development of micro cracks on the surface, which can have a strong influence on the material properties. SEM investigation of the $1000{ }^{\circ} \mathrm{C}$ samples shows a uniform geometry of the surface and no specific changes can be observed due to their amorphous nature. In the case of samples pyrolysed at $1400{ }^{\circ} \mathrm{C}$, fibre like structures, distributed on the surface of samples can be seen in SEM images corresponding to nanocrystalline $\mathrm{SiC}$, formed due to carbothermal reduction reaction as presented in eq 4.1 and 4.2. Formation of these whiskers at higher pyrolysis temperatures are reported in many literatures and the presence of high carbon content in the ceramics act as its main source. High resolution FESEM measurements clearly show the formation of whisker like structures resulting in formation of smaller pits and micro cracks on the surface. Long whiskers can be seen with an average thickness of around $100 \mathrm{~nm}$ and several micrometers in length. These microcracks and $\mathrm{SiC}$ whiskers can be seen randomly distributed on the surface of $1400^{\circ} \mathrm{C}$ SiOC samples, making it more brittle with reduced mechanical strength. 
a)
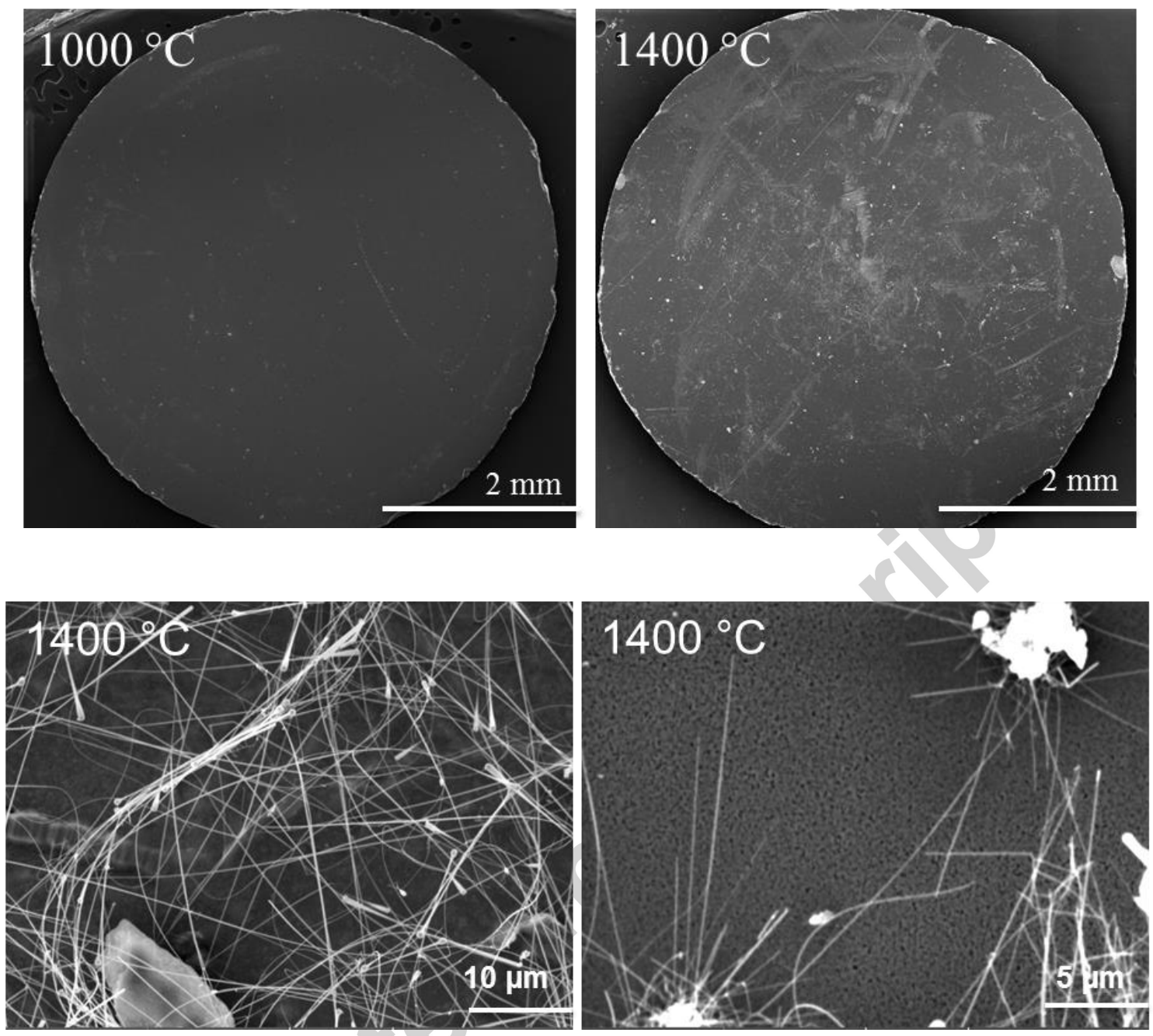

b)
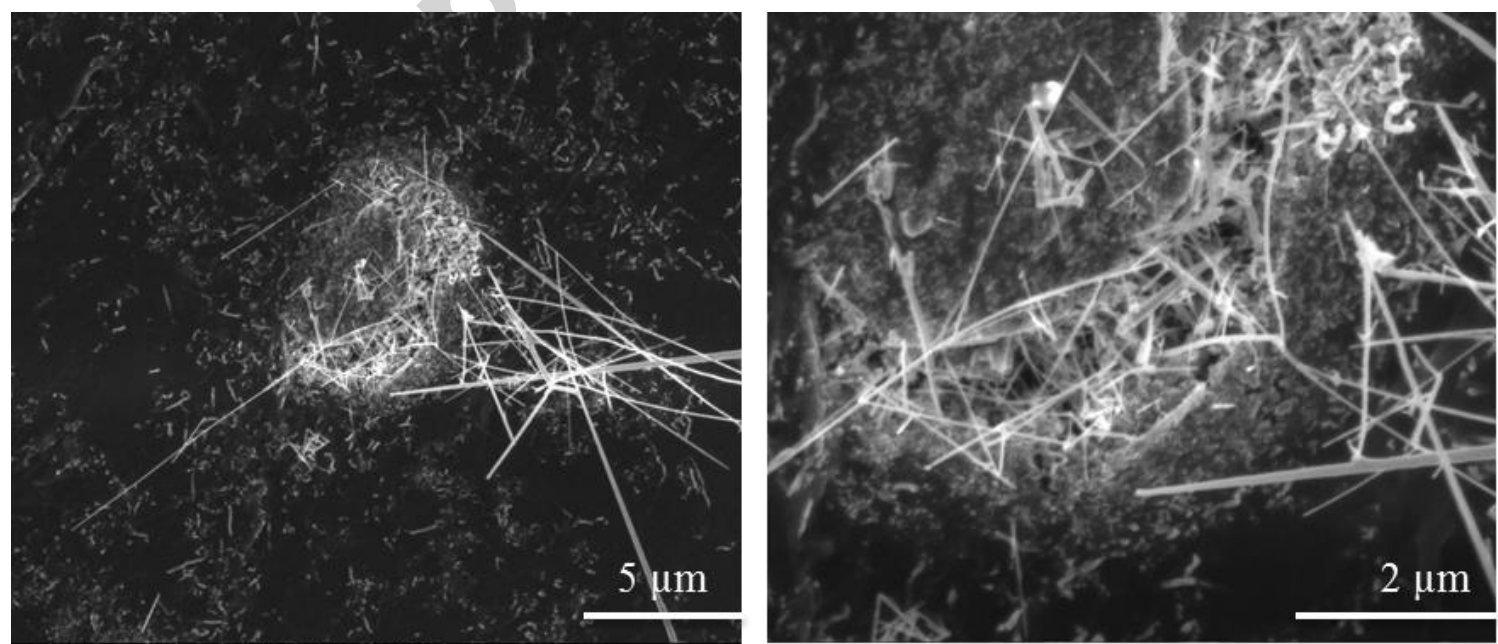

Figure 4. a) SEM I mages of 1000 and $1400^{\circ} \mathrm{C}$ pyrolysed SiOC ceramics, b) FESEM images of 1400

${ }^{\circ} \mathrm{C}$ samples. 
Raman spectra of SiOC ceramic monoliths pyrolysed from $800-1400{ }^{\circ} \mathrm{C}$ are presented in Figure 5. The spectra show features similar to disordered carbons with two strong peaks at the D-band (at $\approx 1350 \mathrm{~cm}-1$ ) and G-band (at $\approx 1600 \mathrm{~cm}-1$ ) respectively. The D-band is due to the disorder induced vibrations of 6-fold aromatic rings and the G-band represents the in plane bond stretching of the sp2 hybridized carbon atoms within the chain structure[15, 40]. With increase in pyrolysis temperature, an increase in $I_{D} / I_{G}$ intensity ratio is observed and $D$ and $G$ bands become narrower with a decrease in FWHM, indicating an ordering and a size growth of the carbon clusters with increasing pyrolysis temperature $[15,40]$.

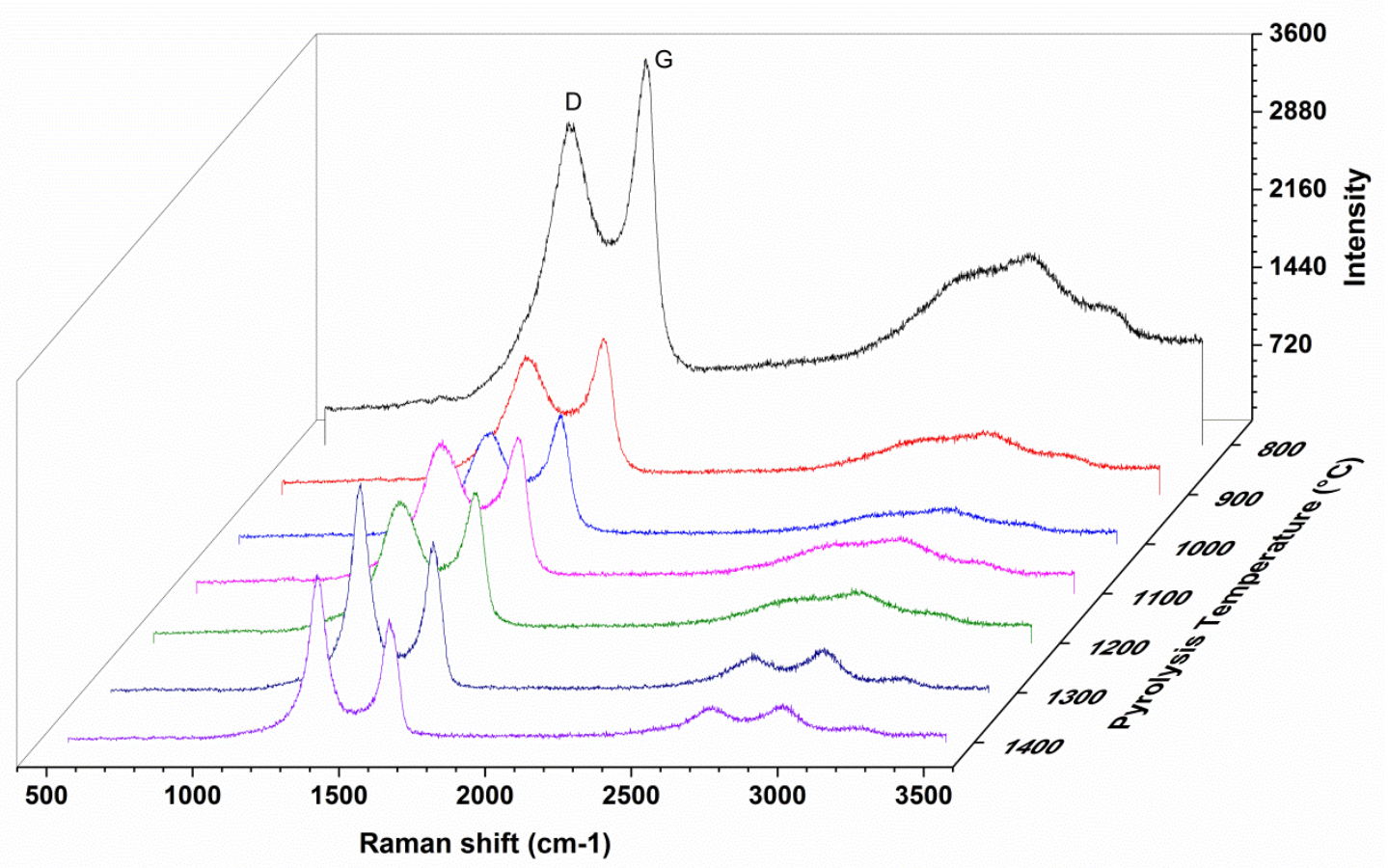

Figure 5. Raman spectra of SiOC samples pyrolysed a t $800-1400{ }^{\circ} \mathrm{C}$.

Mechanical characterisation using B3B method reveals the influence of phase separation on the strength of SiOC ceramics. The Weibull diagram with probability of failure is presented in Figure 
6, calculated from measurements using 15 test samples. Characteristic strength $(\sigma)$ and Weibull modulus $(\mathrm{m})$ are also presented in Figure 5 . Samples pyrolysed at $1000{ }^{\circ} \mathrm{C}$ have a characteristic flexural strength of $922 \mathrm{MPa}$ with a Weibull modulus of 7.4. This significantly higher strength is due to the presence of a high amount of free carbon in the amorphous ceramic network due to the use of DVB as starting precursor. A total free carbon content in the range of $50 \mathrm{wt} \%$ is reported for SiOC ceramics derived from PHMS/DVB composition along with remaining amorphous $\mathrm{SiC}_{x} \mathrm{O}_{2(1-x)}$ phase[15]. Flexural strength is found to be lower for $1400^{\circ} \mathrm{C}$ samples, with $\sigma=295 \mathrm{MPa}$ and $\mathrm{m}=2.5$ and the reason for the reduced mechanical strength is mainly attributed to the formation of microcracks on the surface due to carbothermal reduction. Presence of microcracks on the surface is visible from FESEM images and these defects makes the ceramics more brittle with reduced strength.

Electrical conductivity is another important factor in determining the application of this material for fabrication of MEMS devices for biological applications. The variation of electrical conductivities of SiOC samples with respect to pyrolysis temperatures is presented in Figure 7. All the measurements have been performed at room temperature. Electrical conductivity of the samples pyrolysed at $800{ }^{\circ} \mathrm{C}$ was of the order of $10^{-7} \mathrm{~S} / \mathrm{cm}$ and this is then found to increase with respect to pyrolysis temperature and a maximum conductivity of $10^{1} \mathrm{~S} \mathrm{~cm}^{-1}$ is observed for $1400{ }^{\circ} \mathrm{C}$ samples. Phase separation and ordering of carbon network is found to have a major role on enhancing the electrical conductivity of the SiOC samples. 


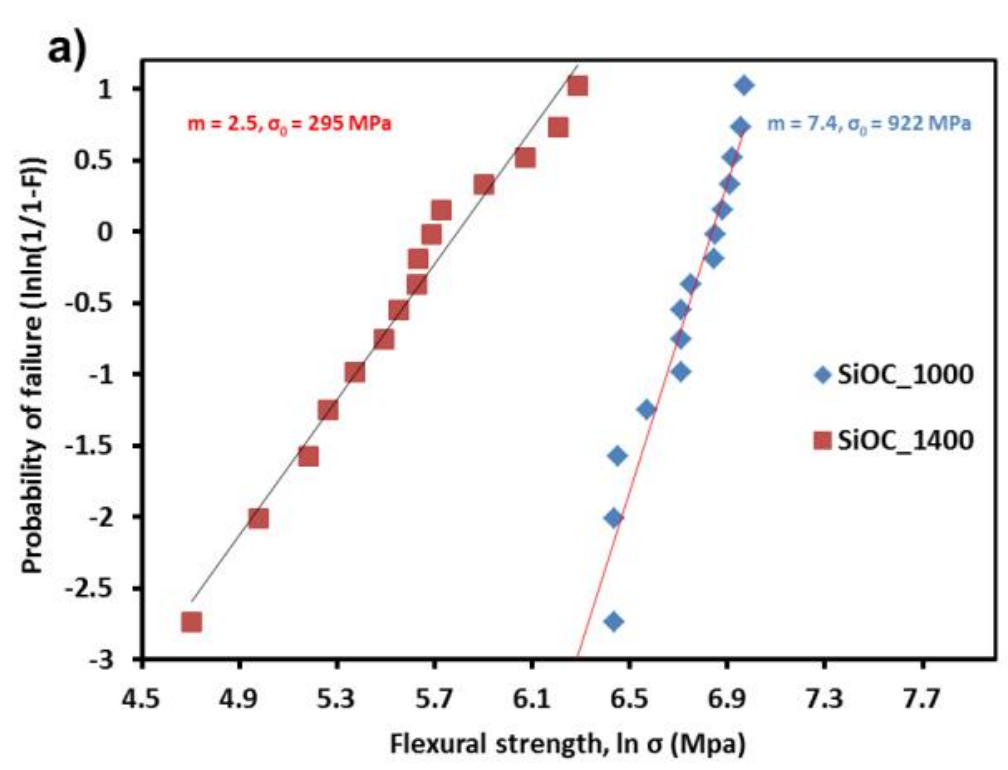

b)

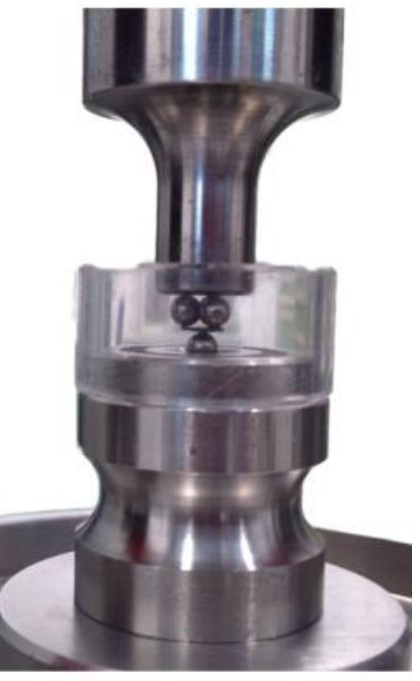

Figure 6. a. Weibull diagram of SiOC samples pyrolysed at 1000 and $1400^{\circ} \mathrm{C}$. b. B3B sample loading for measurement of flexural strength

The increase in electrical conductivity with respect to pyrolysis temperatures is mainly attributed to the process of carbonization with more ordering in the disordered carbon network as seen from the Raman spectra in Figure 5. Changes in ordering of free carbon network along with an increase in crystallite size at higher pyrolysis temperatures have also been previously reported for SiOC ceramics with the help of Raman spectroscopy and diffraction techniques [15, 24].

SiOC materials have already proven its potential to apply as materials for industrial applications demanding conductivity and mechanical strength [22, 29, 31, 41-45]. Microstructure developments during pyrolysis have a key role in deciding its physical and chemical properties. Correlation of materials properties with microstructure development is important for designing 
ceramic microstructures for various applications. Elemental $\mathrm{Si}, \mathrm{O}, \mathrm{C}$ composition of final ceramics are well controlled by choosing ideal starting polymer precursors.

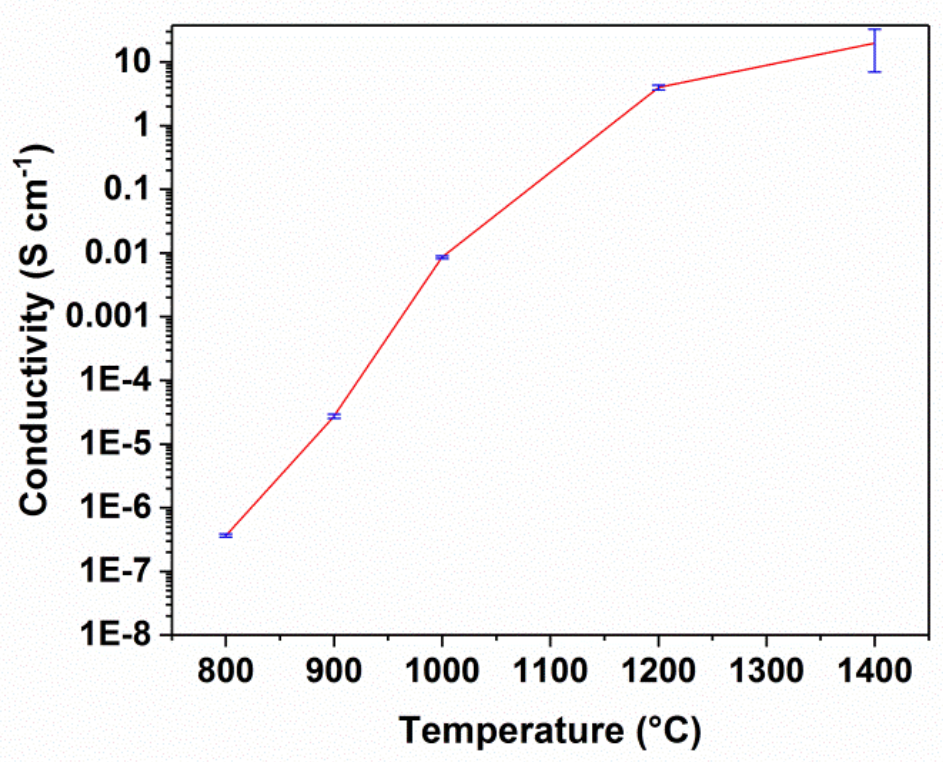

Figure 7. Electrical conductivities of samples pyrolysed from $800-1400{ }^{\circ} \mathrm{C}$

Addition of divinylbenzene (DVB) for PCP synthesis leads to C-rich SiOC ceramic compositions, which in turn enhances various material properties $[15,46]$. Pyrolysis temperature also has an important role in determining structural properties of SiOC ceramics and the phase separations happening at higher temperatures are well explained in many literatures using the support of Raman spectra, TEM and MAS NMR techniques $[1,14,15,47,48]$. Changes in the microstructure at higher temperatures found to have positive influence on the electrical conductivity due to the ordering of free carbon in the material but mechanical characterizations of SiOC discs have revealed a negative influence of phase separation on the mechanical properties of SiOC ceramics with material turning weaker in nature and exhibit a reduced flexural strength. Randomly distributed microcracks developed on SiOC ceramic discs after 
pyrolysis at $1400{ }^{\circ} \mathrm{C}$ due to SiC formation leads to poor Weibull modulus and reduced characteristic strength.

Tailoring the materials structure by incorporating nanofillers may further improve the properties of PDC SiOC ceramics to find applications in next generation bioimplants such as applications in pacemaker electrodes, micromotors, neuro sensors etc. Detailed biocompatibility studies are in progress to obtain a clear picture of the blood material interaction.

\section{Conclusions}

PDC SiOC monoliths in the form of $5 \mathrm{~mm}$ circular discs have been synthesized by pyrolysis of crosslinked preceramic green bodies at temperatures above $1000^{\circ} \mathrm{C}$. Structural characterization of the material using FTIR, XRD and microscopy imaging confirms the phase separation process occurs at higher temperatures with formation of nanocrystalline SiC. Significant differences in microstructure are observed between the samples pyrolysed at $1000^{\circ} \mathrm{C}$ and $1400{ }^{\circ} \mathrm{C}$. Electrical conductivity of the SiOC samples was found to increase with the pyrolysis temperature and a maximum conductivity of $10^{1} \mathrm{~S} \mathrm{~cm}^{-1}$ was observed for samples pyrolysed at $1400{ }^{\circ} \mathrm{C}$. SiOC exhibits higher mechanical strength at $1000{ }^{\circ} \mathrm{C}$ with a characteristic strength of $922 \mathrm{MPa}$. Characteristic strength was found to be reduced for samples pyrolysed $1400^{\circ} \mathrm{C}$ due to the onset of carbothermal reduction, forming pits and micro cracks on the surface of the ceramic discs. From the preliminary characterizations, it can be concluded that there is indeed a pronounced effect of phase separation on the properties of PDC materials. A detailed analysis of phase separation from amorphous to crystalline ceramics is important to further optimize the composition and ideal sintering conditions. Based on our findings, amorphous PDC SiOC 
ceramics pyrolysed at $1000^{\circ} \mathrm{C}$ can be considered as a potential candidate for applications in bio environments and for fabrication in to biomedical implants.

\section{Acknowledgments}

This work was supported by the Strategic Focus Area (SFA) Advanced Manufacturing programme under the project named Ceramic X.O High-precision micro-manufacturing of ceramics.

\section{References}

[1] P. Colombo, G. Mera, R. Riedel, G.D. Soraru, Polymer-Derived Ceramics: 40 Years of Research and Innovation in Advanced Ceramics, Journal of the American Ceramic Society, 93 (2010) 1805-1837.

[2] Y.D. Blum, D.B. MacQueen, H.J. Kleebe, Synthesis and characterization of carbon-enriched silicon oxycarbides, Journal of the European Ceramic Society, 25 (2005) 143-149.

[3] H. Brequel, J. Parmentier, G.D. Sorar, L. Schiffini, S. Enzo, Study of the phase separation in amorphous silicon oxycarbide glasses under heat treatment, Nanostructured Materials, 11 (1999) 721-731.

[4] E. Breval, M. Hammond, C.G. Pantano, NANOSTRUCTURAL CHARACTERIZATION OF SILICON OXYCARBIDE GLASSES AND GLASS-CERAMICS, Journal of the American Ceramic Society, 77 (1994) 30123018.

[5] R.J.P. Corriu, D. Leclercq, P.H. Mutin, A. Vioux, SI-29 NUCLEAR-MAGNETIC-RESONANCE STUDY OF THE STRUCTURE OF SILICON OXYCARBIDE GLASSES DERIVED FROM ORGANOSILICON PRECURSORS, Journal of Materials Science, 30 (1995) 2313-2318.

[6] F.I. Hurwitz, P. Heimann, S.C. Farmer, D.M. Hembree, CHARACTERIZATION OF THE PYROLYTIC CONVERSION OF POLYSILSESQUIOXANES TO SILICON OXYCARBIDES, Journal of Materials Science, 28 (1993) 6622-6630.

[7] E. Ionescu, S. Sen, G. Mera, A. Navrotsky, Structure, energetics and bioactivity of silicon oxycarbidebased amorphous ceramics with highly connected networks, Journal of the European Ceramic Society, 38 (2018) 1311-1319.

[8] C.G. Pantano, A.K. Singh, H. Zhang, Silicon Oxycarbide Glasses, Journal of Sol-Gel Science and Technology, 14 (1999) 7-25.

[9] E. Radovanovic, M.F. Gozzi, M.C. Goncalves, I.V.P. Yoshida, Silicon oxycarbide glasses from silicone networks, Journal of Non-Crystalline Solids, 248 (1999) 37-48.

[10] M.A. Schiavon, S.U.A. Redondo, S.R.O. Pina, I.V.P. Yoshida, Investigation on kinetics of thermal decomposition in polysiloxane networks used as precursors of silicon oxycarbide glasses, Journal of NonCrystalline Solids, 304 (2002) 92-100.

[11] G.D. Soraru, L. Pederiva, M. Latournerie, R. Raj, Pyrolysis kinetics for the conversion of a polymer into an amorphous silicon oxycarbide ceramic, Journal of the American Ceramic Society, 85 (2002) 21812187.

[12] R. Pena-Alonso, G. Mariotto, C. Gervais, F. Babonneau, G.D. Soraru, New insights on the hightemperature nanostructure evolution of SiOC and B-doped SiBOC polymer-derived glasses, Chemistry of Materials, 19 (2007) 5694-5702. 
[13] M.C. Bechelany, V. Proust, A. Lale, P. Miele, S. Malo, C. Gervais, S. Bernard, Nanocomposites through the Chemistry of Single-Source Precursors: Understanding the Role of Chemistry behind the Design of Monolith-Type Nanostructured Titanium Nitride/Silicon Nitride, Chemistry - A European Journal, 23 (2017) 832-845.

[14] S.J. Widgeon, S. Sen, G. Mera, E. lonescu, R. Riedel, A. Navrotsky, Si-29 and C-13 Solid-State NMR Spectroscopic Study of Nanometer-Scale Structure and Mass Fractal Characteristics of Amorphous Polymer Derived Silicon Oxycarbide Ceramics, Chemistry of Materials, 22 (2010) 6221-6228.

[15] V.S. Pradeep, M. Graczyk-Zajac, R. Riedel, G.D. Soraru, New Insights in to the Lithium Storage Mechanism in Polymer Derived SiOC Anode Materials, Electrochimica Acta, 119 (2014) 78-85.

[16] A. Karakuscu, A. Ponzoni, R. Aravind Parakkulam, G. Sberveglieri, D. Soraru Gian, Gas Sensing Behavior of Mesoporous SiOC Glasses, Journal of the American Ceramic Society, 96 (2013) 2366-2369.

[17] M. Wilamowska, V.S. Pradeep, M. Graczyk-Zajac, R. Riedel, G.D. Sorarù, Tailoring of SiOC composition as a way to better performing anodes for Li-ion batteries, Solid State Ionics, 260 (2014) 94100.

[18] J. Grossenbacher, M.R. Gullo, F. Dalcanale, G. Blugan, J. Kuebler, S. Lecaude, H.T. Stahel, J. Brugger, Cytotoxicity evaluation of polymer-derived ceramics for pacemaker electrode applications, Journal of Biomedical Materials Research Part A, 103 (2015) 3625-3632.

[19] R. Zhuo, P. Colombo, C. Pantano, E.A. Vogler, Silicon oxycarbide glasses for blood-contact applications, Acta Biomaterialia, 1 (2005) 583-589.

[20] Z.C. Eckel, C. Zhou, J.H. Martin, A.J. Jacobsen, W.B. Carter, T.A. Schaedler, Additive manufacturing of polymer-derived ceramics, Science, 351 (2016) 58-62.

[21] L. Zoli, D. Sciti, L.A. Liew, K. Terauds, S. Azarnoush, R. Raj, G. Soraru, Additive Manufacturing of Ceramics Enabled by Flash Pyrolysis of Polymer Precursors with Nanoscale Layers, Journal of the American Ceramic Society, 99 (2015) 57-63.

[22] F. Dalcanale, J. Grossenbacher, G. Blugan, M.R. Gullo, A. Lauria, J. Brugger, H. Tevaearai, T. Graule, $M$. Niederberger, J. Kuebler, Influence of carbon enrichment on electrical conductivity and processing of polycarbosilane derived ceramic for MEMS applications, Journal of the European Ceramic Society, 34 (2014) 3559-3570.

[23] E. lonescu, C. Terzioglu, C. Linck, J. Kaspar, A. Navrotsky, R. Riedel, Thermodynamic Control of Phase Composition and Crystallization of Metal-Modified Silicon Oxycarbides, Journal of the American Ceramic Society, 96 (2013) 1899-1903.

[24] J. Kaspar, M. Graczyk-Zajac, S. Choudhury, R. Riedel, Impact of the electrical conductivity on the lithium capacity of polymer-derived silicon oxycarbide (SiOC) ceramics, Electrochimica Acta, 216 (2016) 196-202.

[25] M. Wilamowska-Zawlocka, P. Puczkarski, Z. Grabowska, J. Kaspar, M. Graczyk-Zajac, R. Riedel, G.D. Soraru, Silicon oxycarbide ceramics as anodes for lithium ion batteries: influence of carbon content on lithium storage capacity, Rsc Advances, 6 (2016) 104597-104607.

[26] S. Martinez-Crespiera, E. Ionescu, H.-J. Kleebe, R. Riedel, Pressureless synthesis of fully dense and crack-free SiOC bulk ceramics via photo-crosslinking and pyrolysis of a polysiloxane, Journal of the European Ceramic Society, 31 (2011) 913-919.

[27] L. Bois, J. Maquet, F. Babonneau, H. Mutin, D. Bahloul, Structural Characterization of Sol-Gel Derived Oxycarbide Glasses. 1. Study of the Pyrolysis Process, Chemistry of Materials, 6 (1994) 796-802.

[28] H. Liu, H. Zhang, J. Li, W. Kang, P. Chu, A novel SiCN@TiO 2 core-shell ceramic microspheres derived from a polymeric precursor, Ceramics International, 42 (2016) 7135-7140.

[29] K. Lu, D. Erb, M. Liu, Phase transformation, oxidation stability, and electrical conductivity of TiO2polysiloxane derived ceramics, Journal of Materials Science, 51 (2016) 10166-10177.

[30] E. Ionescu, A. Francis, R. Riedel, Dispersion assessment and studies on AC percolative conductivity in polymer-derived Si-C-N/CNT ceramic nanocomposites, Journal of Materials Science, 44 (2009) 20552062. 
[31] L.W. Yang, X.S. Zhang, H.T. Liu, M. Zu, Thermal resistant, mechanical and electrical properties of a novel ultrahigh-content randomly-oriented CNTs reinforced SiC matrix composite-sheet, Composites Part B: Engineering, 119 (2017) 10-17.

[32] I. Gonzalo-Juan, R. Detsch, S. Mathur, E. Ionescu, A.R. Boccaccini, R. Riedel, Synthesis and In Vitro Activity Assessment of Novel Silicon Oxycarbide-Based Bioactive Glasses, Materials, 9 (2016).

[33] P.R. Willmott, D. Meister, S.J. Leake, M. Lange, A. Bergamaschi, M. Boge, M. Calvi, C. Cancellieri, N. Casati, A. Cervellino, Q. Chen, C. David, U. Flechsig, F. Gozzo, B. Henrich, S. Jaggi-Spielmann, B. Jakob, I. Kalichava, P. Karvinen, J. Krempasky, A. Ludeke, R. Luscher, S. Maag, C. Quitmann, M.L. Reinle-Schmitt, T. Schmidt, B. Schmitt, A. Streun, I. Vartiainen, M. Vitins, X. Wang, R. Wullschleger, The Materials Science beamline upgrade at the Swiss Light Source, Journal of Synchrotron Radiation, 20 (2013) 667-682.

[34] A. Börger, P. Supancic, R. Danzer, The ball on three balls test for strength testing of brittle discs: Part II: analysis of possible errors in the strength determination, Journal of the European Ceramic Society, 24 (2004) 2917-2928.

[35] A. Börger, P. Supancic, R. Danzer, The ball on three balls test for strength testing of brittle discs: stress distribution in the disc, Journal of the European Ceramic Society, 22 (2002) 1425-1436.

[36] R. Danzer, W. Harrer, P. Supancic, T. Lube, Z. Wang, A. Börger, The ball on three balls test-Strength and failure analysis of different materials, Journal of the European Ceramic Society, 27 (2007) 1481-1485. [37] Q. Liu, W. Shi, F. Babonneau, L.V. Interrante, Synthesis of polycarbosilane/siloxane hybrid polymers and their pyrolytic conversion to silicon oxycarbide ceramics, Chemistry of Materials, 9 (1997) 24342441.

[38] M. Scheffler, T. Gambaryan-Roisman, T. Takahashi, J. Kaschta, H. Muenstedt, P. Buhler, P. Greil, Pyrolytic decomposition of preceramic organo polysiloxanes, in: N. Bansal, J.P. Singh (Eds.) Innovative Processing and Synthesis of Ceramics, Glasses, and Composites Iv2000, pp. 239-250.

[39] R.J.P. Corriu, D. Leclercq, P.H. Mutin, A. Vioux, Preparation and structure of silicon oxycarbide glasses derived from polysiloxane precursors, Journal of Sol-Gel Science and Technology, 8 (1997) 327330.

[40] A.C. Ferrari, J. Robertson, Interpretation of Raman spectra of disordered and amorphous carbon, Physical Review B, 61 (2000) 14095-14107.

[41] K. Lu, D. Erb, M. Liu, Thermal stability and electrical conductivity of carbon-enriched silicon oxycarbide, Journal of Materials Chemistry C, 4 (2016) 1829-1837.

[42] G.D. Soraru, G. Kacha, R. Campostrini, A. Ponzoni, M. Donarelli, A. Kumar, G. Mariotto, The effect of B-doping on the electrical conductivity of polymer-derived $\mathrm{Si}(\mathrm{B}) \mathrm{OC}$ ceramics, Journal of the American Ceramic Society, 100 (2017) 4611-4621.

[43] V. Bakumov, G. Blugan, S. Roos, T. Graule, V. Fakhfouri, J. Grossenbacher, M. Gullo, T. Kiefer, J. Brugger, M. Parlinska, J. Kuebler, Mechanical and tribological properties of polymer-derived Si/C/N submillimetre thick miniaturized components fabricated by direct casting, Journal of the European Ceramic Society, 32 (2012) 1759-1767.

[44] P. Colombo, J.R. Hellmann, D.L. Shelleman, Mechanical properties of silicon oxycarbide ceramic foams, Journal of the American Ceramic Society, 84 (2001) 2245-2251.

[45] G.D. Soraru, E. Dallapiccola, G. Dandrea, Mechanical characterization of sol-gel-derived silicon oxycarbide glasses, Journal of the American Ceramic Society, 79 (1996) 2074-2080.

[46] H.-J. Kleebe, Y.D. Blum, SiOC ceramic with high excess free carbon, Journal of the European Ceramic Society, 28 (2008) 1037-1042.

[47] G. Mera, M. Gallei, S. Bernard, E. Ionescu, Ceramic Nanocomposites from Tailor-Made Preceramic Polymers, Nanomaterials, 5 (2015) 468.

[48] R. Riedel, G. Mera, R. Hauser, A. Klonczynski, Silicon-based polymer-derived ceramics: Synthesis properties and applications - A review, Journal of the Ceramic Society of Japan, 114 (2006) 425-444. 
Tables

\begin{tabular}{cccccc}
\hline \multirow{2}{*}{$\begin{array}{c}\text { Pyrolysis } \\
\text { temperature }\left({ }^{\circ} \mathrm{C}\right)\end{array}$} & Diameter before & Diameter after & Ceramic & Volumetric & Density \\
& pyrolysis $(\mathrm{mm})$ & pyrolysis $(\mathrm{mm})$ & yield & Shrinkage & $(\mathrm{g} / \mathrm{cm}$ \\
\hline 1000 & 7 & & $(\%)$ & $(\%)$ & $\left.{ }^{3}\right)$ \\
1400 & 7 & 5.0 & 71 & 63 & 1.52 \\
\hline
\end{tabular}

Table 1. Ceramic yield, shrinkage and geometrical density of SiOC samples pyrolysed at 1000 and $1400^{\circ} \mathrm{C}$. 


\section{Figure Captions}

1. Figure 1. a. Schematic representation of the PDC fabrication process and b. proposed hydrosililation reaction scheme

2. Figure 2. FTIR spectra of preceramic greenbody and samples pyrolysed at 1000 and 1400 ${ }^{\circ} \mathrm{C}$ respectively

3. Figure 3. Diffraction pattern of preceramic greenbody and samples sintered at 800,900 , $1000,1100,1200,1300$ and $1400{ }^{\circ} \mathrm{C}$ respectively. Patterns are linearly shifted along the $y$ axis (arbitrary units) from the preceramic green body to the highest temperature for better reading

4. Figure 4. a) SEM Images of 1000 and $1400{ }^{\circ} \mathrm{C}$ pyrolysed SiOC ceramics, b) FESEM images of $1400^{\circ} \mathrm{C}$ samples.

5. Figure 5 . Raman spectra of SiOC samples pyrolysed at $800-1400{ }^{\circ} \mathrm{C}$.

6. Figure 6. a. Weibull diagram of SiOC samples pyrolysed at 1000 and $1400{ }^{\circ} \mathrm{C}$. b. B3B sample loading for measurement of flexural strength

7. Figure 7. Room temperature electrical conductivities of SiOC pyrolysed from 800 - 1400 ${ }^{\circ} \mathrm{C}$ 